\title{
Paediatric RIFLE and AKIN Classification for Detection and Outcome of Acute Kidney Injury in Critically Sick Children. Which is Better? A Prospective Cohort Study
}

\author{
Thakkar PA ${ }^{1}$, Pandey ${ }^{2}$, Shringarpure KS $^{3}$
}

\begin{abstract}
Introduction: Acute Kidney Injury (AKI) is becoming increasingly common in both developed and developing countries with significant morbidity and mortality. However, the precise incidence of $\mathrm{AKI}$ in children is not well known due to lack of uniformity in various definitions of AKI. This study was carried out to compare incidence of AKI using two different definitions-pRIFLE and AKIN. Material and Methods: This was a prospective cohort study conducted in the paediatric ICU of a tertiary care government hospital attached to a Medical College of Central Gujarat, India. Total 115 critically ill paediatric patients aged one month to 12 years were included in the study. Serum Creatinine (SCr) levels were tested and Glomerular filtration rate (GFR) was calculated using the Schwartz formula at $0,6,12,24$ and 48 hours of admission. Patients were assessed for AKI using AKIN and pRIFLE classification. Results: Incidence of AKI was $80 \%$ and $66.9 \%$ in critically ill children, as classified by pRIFLE and AKIN classification respectively. Paediatric RIFLE labelled 15 more patients as AKI which were classified as non-AKI by AKIN criteria. There was moderate agreement in between the two classifications to diagnose stages of AKI (Kappa 0.474, CI0.359 to 0.589 ). With increasing grades of AKI, mortality was higher using pRIFLE staging; unlike the AKIN staging wherein this was not observed. Conclusion: The pRIFLE criteria detects a greater number of cases of AKI compared to AKIN criteria. Based on severity staging, pRIFLE is more consistent with adverse outcome of patients with AKI compared to AKIN classification. Overall mortality is significant high in patients with AKI compared to patients without AKI using any of the classifications.
\end{abstract}

Keywords: Acute Kidney Injury, Acute Kidney Injury Network, Paediatric intensive care unit, Paediatric RIFLE, mortality
${ }^{1}$ Dr. Pareshkumar A Thakkar, MD, DNB, DCH, Associate Professor, Department of Paediatrics, Medical College and SSG Hospital, Vadodara, Gujarat, India, ${ }^{2} \mathrm{Dr}$. Neha Pandey, MD, Fellow in Neonatology, University Hospital Wales, Cardiff, U.K., ${ }^{3}$ Dr. Kalpita S Shringarpure, MD, MBA, CIH, Tutor, Department of PSM, Medical College Baroda.

\author{
Address for correspondence \\ Dr. Kalpita S Shringarpure \\ Medical College Baroda, Raopura, \\ Anandpura, Baroda, Gujarat 390001 \\ India \\ Tel No: +919824673141 \\ E-mail: kshringarpure@gmail.com
}

\author{
Acknowledgements: None \\ Funding: Nil \\ Conflict of Interest: None \\ Permission from IRB: Yes
}

\begin{abstract}
How to cite
Thakkar PA, Pandey N, Shringarpure KS. Paediatric RIFLE and AKIN Classification for Detection and Outcome of Acute Kidney Injury in Critically Sick Children. Which Is Better? A Prospective Cohort Study. J Nepal Paediatr Soc 2018;38(1):31-37.
\end{abstract}

doi: http://dx.doi.org/10.3126/jnps.v38i1.19767

\section{Introduction}

A cute Kidney Injury (AKI) has become increasingly common Ain both developed and developing countries with significant morbidity and mortality ${ }^{1}$. The precise incidence of $\mathrm{AKI}$ in children is not well known ${ }^{1}$. Prospective studies from India suggest an incidence of
This work is licensed under a Creative Commons Attribution 3.0 License. 
4-6\% of $\mathrm{AKI}$ in paediatric patients in general wards and up to $60 \%$ in Pediatric Intensive Care Units (PICUs) ${ }^{2,3,4,5}$. $\mathrm{AKI}$, earlier known as acute renal failure (ARF) is a term used for an abrupt and sustained decrease in glomerular filtration rate (GFR) resulting in retention of nitrogenous (urea and creatinine) and non-nitrogenous waste products ${ }^{6}$. Clinicians and paediatricians mostly use Serum Creatinine (SCr) values to analyse renal status which in fact is not a sensitive parameter. Normal $\mathrm{SCr}$ values in children being age dependent and usually on the lower side, elevated SCr is often misinterpreted as normal and thus, timely intervention is missed leading to further progression causing increased morbidity and mortality. It is now evident that even minimal change in $\mathrm{SCr}$ and GFR are associated with a dramatic increase in mortality ${ }^{6}$. Earlier Identification of $\mathrm{AKI}$ in patients or 'at risk' for AKI patients can definitely help in deciding the management and installing measures to prevent further renal injury; like avoiding nephrotoxic drugs and appropriate fluid management, and, thereby preventing morbidity and mortality arising due to it. The reported mortality from AKI is still as high as $60 \%$ in critically ill children. ${ }^{7}$ The lack of a precise biochemical definition of ARF resulted in at least 35 definitions in the medical literature $^{8}$, which gave rise to a wide variation in reported incidence and clinical significance of ARF and impeded a meaningful comparison of studies that assess preventive and therapeutic strategies. As there was no standardized definition of AKI, Acute Dialysis Quality Initiative Group devised the Risk, Injury, Failure, Loss, End Stage Renal Disease (RIFLE) criteria in 2004 , which were subsequently modified in 2007 . The first modification viz. 'the paediatric RIFLE (pRIFLE)' was made to adapt this definition for its use in children ${ }^{3}$. The RIFLE system defines AKI by a change in $\mathrm{SCr}$ level or eGFR from a baseline value and urine output per kilogram of body weight over a specified time period $^{9}$. The second modification was made by Acute Kidney Injury Network (AKIN) which defined AKI based on the RIFLE system but adds an absolute change in $\mathrm{SCr}$ of $\geq 0.3 \mathrm{mg} / \mathrm{dL}$, omits eGFR criteria and includes a time constraint of 48 hours $^{10}$. The AKIN system also omits the stages "Loss" and "End-stage" and allocates patients who needed acute dialysis to stage- $3^{11}$. Despite modifications considered under these definitions, none of them has been proven superior and accepted as a universal standardized definition. There are studies with totally different definitions of AKI based on absolute change in $\mathrm{SCr}$ rather than relative change in $\mathrm{SCr}^{12}$. There are few studies comparing definitions of $\mathrm{AKI}$ in adults $^{10,13,14,15}$, but very limited studies comparing them in children especially from developing countries ${ }^{14}$.The aim of this study was to compare classification of Acute Kidney Injury using two different definitions - pRIFLE and AKIN in terms of incidence and outcome of critically sick children.

\section{Material and Methods}

This is a prospective cohort study carried out at Paediatric intensive care unit of a tertiary care hospital, attached to a Government Medical College of Central Gujarat, India. This study was carried out over a period of six months from April 2013 to September 2013. Ethical clearance was obtained from Institutional Ethics Committee on Human Research. Critically ill children of age one month to 12 years admitted in Paediatric intensive Care unit during this period were included in the study. Patients with chronic kidney diseases, S. Bilirubin $>5 \mathrm{mg} / \mathrm{dL}$ and patients with hospital stay for less than 24 hours were excluded from study. They were enrolled after obtaining informed written consent form parents. Sample size was deduced using $5 \%$ allowable error $(\alpha)$ and power of study ( $\beta$ ) $80 \%$. The incidence of $\mathrm{AKI}$ in children is approximately $5 \%$ among non-critically ill ${ }^{16,17}$ and $30 \%$ in critically ill ${ }^{18,19}$. In order to estimate these incidence rates at $95 \%$ confidence, the required sample size was 104 . Expecting $10 \%$ refusal and loss to follow up, the estimated sample size was 115. In the study period, we screened 146 patients, of which 115 were enrolled in the study. Patients' demographic characteristics, clinical profile, physiological parameters, laboratory investigations, outcome data and necessary information were recorded in a pre-designed performa. $\mathrm{SCr}$ was estimated on Mura 300 auto-analyser by modified Jaffe method ${ }^{20}$ at admission and then at 6 , 12, 24 and 48 hours of admission. Subsequently, the estimation was done at daily interval in patients with AKI. Baseline SCr was determined by using backward calculation as recommended by Kidney Disease Improving Global Outcomes Group (KDIGO) ${ }^{14}$ from the normal GFR for the given age (for paediatric population). These standardized GFR values were also taken as the baseline GFR for purpose of staging of patients according to pRIFLE criteria. Estimated creatinine clearance $(\mathrm{eCCl})$ were calculated at $6,12,24$, and 48 of admission using the Schwartz formula ${ }^{21}$. Urine output criteria were not applied. Data of the patients were reviewed daily and patients were assigned to the appropriate pRIFLE strata (R, I or, F), AKIN staging (Stage I, II, III) $)^{9,22}$. In case the patients progressed from a milder stage to a more severe stage of $\mathrm{AKI}$, the worst or the most severe category was assigned for pRIFLE and AKIN staging respectively.

Statistical Analysis: Data was entered in MS Excel 2007 and analysed using SPSS software version 18 which is a statistical analytical tool ${ }^{23}$. Incidence of AKI and demographic characteristics were expressed in terms of 
percentages and proportions. Agreement between the two classifications for staging of AKI was calculated using Kappa statistic. Probability value ( $p$-value) less than 0.05 was considered statistically significant.

\section{Results}

Characteristics of the study cohort: Out of 146 patients screened, 31 did not meet the inclusion criteria and were excluded (due to hospital stay being less than 48 hours (8), mortality within 48 hours (10), chronic kidney condition (7) and Serum bilirubin $>5 \mathrm{mg} /$ dl (6) Figure 1. Of 115 patients included in this study, $70(60.8 \%)$ were discharged, $38(33.04 \%)$ expired and seven $(6.05 \%)$ left against medical advice. There were $43(37.3 \%)$ females and $72(62.6 \%)$ males.

AKI incidence: In the cohort of 115 patients, 92 (80\%) and $77(66.9 \%)$ of patients were detected to have AKI by pRIFLE criteria and AKIN criteria respectively. In the first stage of AKI, 29 (25.3\%) patients were classified as per pRIFLE compared to $39(34 \%)$ as per AKIN. Thirty eight $(33 \%)$ and $16(14 \%)$ patients were in stage II while $25(21.7 \%)$ and $22(19 \%)$ were in stage III by pRIFLE and AKIN respectively (Table 1). Paediatric RIFLE classification also detected $92.4 \%$ (85/92) cases of $A K I$ at six hours compared to $85.7 \%(66 / 77)$ cases by AKIN criteria.

Stage of $A K I$ and outcome: Of the 115 patients included in this study, 38 (33.04\%) expired. Renal replacement therapy was needed in three out of 92 patients of AKI. All of these patients were classified as "failure" category of AKI by pRIFLE classification. Two out of these three patients expired while one patient; whose peritoneal dialysis was done for four days, was discharged.

The overall mortality rate of patients with AKI (pRIFLE) was $39.1 \%(n=36 / 92)$ while that in nonAKI patients was $5.3 \%(n=2 / 23)$ (Chi-square $=7.64, p$ value 0.005 ). Mortality rate among patients classified as having $\mathrm{AKI}$ as per AKIN classification was $42.8 \%$ $(n=33 / 77)$ and in non-AKI patients was $13.2 \%(n=5 / 38)$ (Chi-square $=10.06, p$-value 0.001 ). Stage wise mortality has been shown in Table 2. With pRIFLE staging, the mortality observer was higher with higher grade of AKI, such relation of outcome was not observed with AKIN staging (Table 2).

Agreement between two definitions: Out of total 115 patients, 23 patients were labelled as non-AKI by both the classification, while pRIFLE labelled 15 more patients as $A K I$ which were classified as non $A K I$ by AKIN criteria. (Table 2). Of these 15 patients labelled as non-AKI by AKIN criteria, 12 patients were in risk category (equivalent to stage I of AKIN) while three patients were in Injury category (equivalent to stage II of AKIN) of pRIFLE and three out of these 15 patients died. Out of 39 patients classified as stage I of AKI by AKIN definition, only 15 were in the Risk category, 20 were in Injury category and four patients were classified as Failure by pRIFLE classification. The strength of agreement between the two classifications was moderate (Number of observed agreements: 69 $(60.00 \%$ of the observations, number of agreements expected by chance: 27.5 (23.92\% of the observations), Kappa $=0.474$,SE of kappa $=0.059,95 \%$ confidence interval: 0.359 to 0.589 .

Table 1: Comparison of critically sick children admitted with Acute Kidney Injury in Pediatric intensive care unit of a tertiary care hospital, classified by pRIFLE versus AKIN classification.

\begin{tabular}{|c|c|c|c|c|c|c|}
\hline & & \multirow[b]{2}{*}{ Total $n=115(38)$} & \multicolumn{4}{|c|}{ pRIFLE } \\
\hline & & & $\begin{array}{c}\text { Non-AKI } \\
n=23(2)\end{array}$ & $\begin{array}{c}\text { Risk } \\
n=29(8)\end{array}$ & $\begin{array}{c}\text { Injury } \\
\mathrm{n}=38(16)\end{array}$ & $\begin{array}{c}\text { Failure } \\
n=25(12)\end{array}$ \\
\hline$A$ & Non-AKI & $n=38(5)$ & $23(2)$ & $12(3)$ & $3(0)$ & $0(0)$ \\
\hline K & Stage 1 & $\mathrm{n}=39(15)$ & $0(0)$ & $15(5)$ & $20(10)$ & $4(0)$ \\
\hline 1 & Stage 2 & $\mathrm{n}=16(8)$ & $0(0)$ & $2(0)$ & $12(6)$ & $2(2)$ \\
\hline $\mathrm{N}$ & Stage 3 & $\mathrm{n}=22(10)$ & $0(0)$ & $0(0)$ & $3(0)$ & $19(10)$ \\
\hline
\end{tabular}

Kappa-0.474, SE of kappa $=0.059,95 \%$ confidence interval: 0.359 to 0.589

${ }^{*}$ Figures in brackets indicates mortality

Table 2: Stage wise mortality among critically sick children admitted with Acute Kidney Injury in Pediatric intensive care unit of a tertiary care hospital, classified by pRIFLE versus AKIN (N=115)

\begin{tabular}{cccc}
\hline pRIFLE stage & Mortality & AKIN stage & Mortality \\
\hline No AKI & $02 / 23(8.7 \%)$ & No AKI & $5 / 38(13.2 \%)$ \\
\hline Risk & $08 / 29(27.6 \%)$ & Stage 1 & $15 / 39(38.5 \%)$ \\
\hline Injury & $16 / 38(42.1 \%)$ & Stage 2 & $08 / 16(50 \%)$ \\
\hline Failure & $12 / 25(48 \%)$ & Stage 3 & $10 / 22(45.5 \%)$ \\
\hline
\end{tabular}




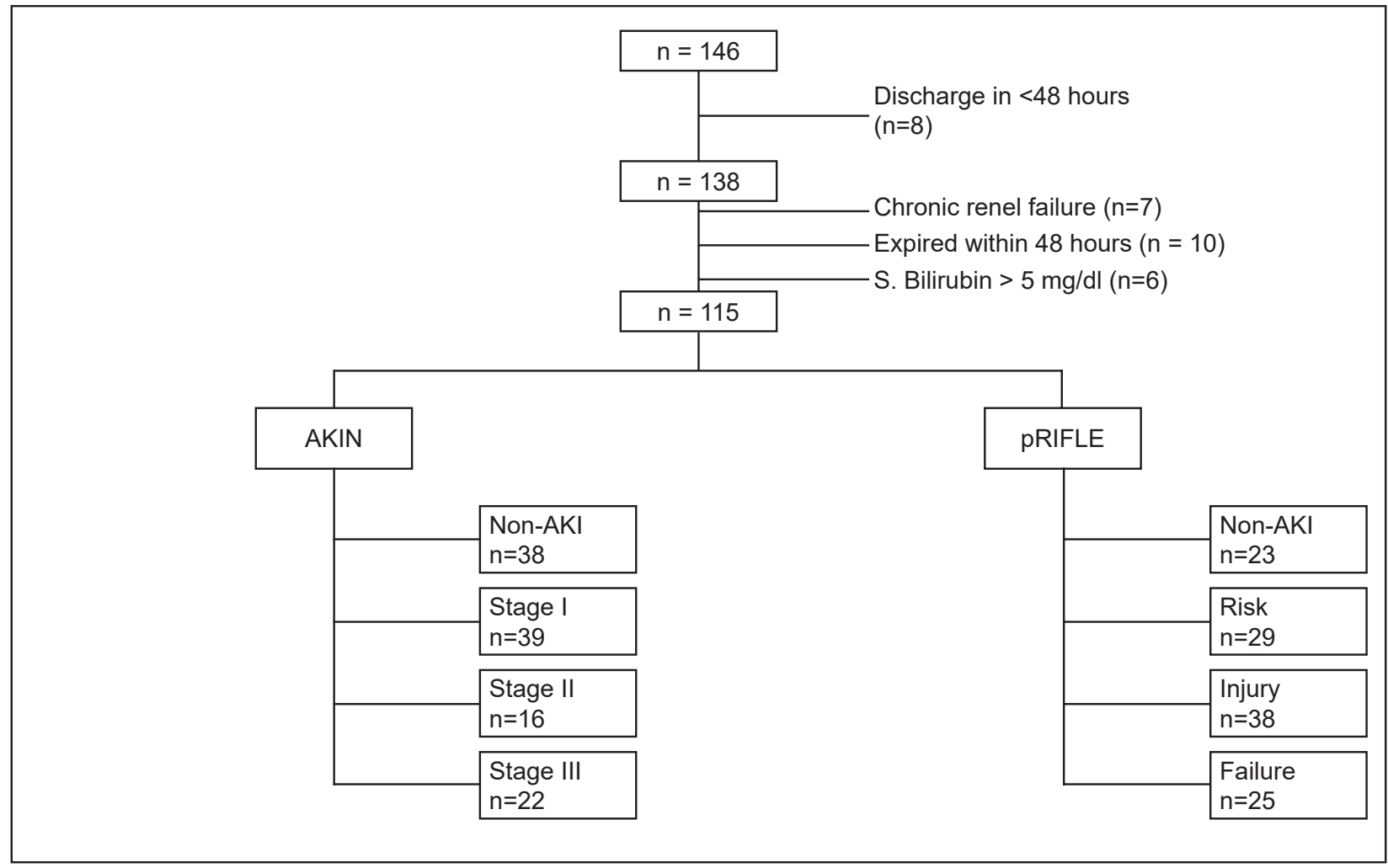

Fig 1: Flow chart of critically sick children admitted with Acute Kidney Injury in Pediatric intensive care unit of a tertiary care hospital, attached to a Government Medical College of Central Gujarat, India ( $\mathrm{N}=146)$.

AKI- Acute kidney injury, AKIN-Acute kidney injury network classification, pRIFLE- Pediatric Risk, Injury, Failure, Loss, End Stage Renal Disease

\section{Discussion}

This study is one of the limited studies conducted among the paediatric groups in India to know the incidence of $\mathrm{AKI}$ and compare the same using two different modified classifications viz. pRIFLE and AKIN in critically ill children.

Paediatric RIFLE not only detected more subjects with $\mathrm{AKI}$, but also had more patients in higher stage of disease compared to AKIN classification. Out of the 115 patients included in this study, more than three fourths (80\%) had AKI as per pRIFLE criteria while two-thirds (66.9\%) had AKI according to AKIN criteria.

A study done at All India Institute of Medical Sciences, New Delhi by Poonam Mehta et a ${ }^{24}$ suggested an incidence of $36.1 \%$ in the critically ill patients. These findings were based on AKIN staging. Another study by WF Hui ${ }^{25}$, using the pRIFLE score estimated the incidence to be $56 \%$ in a paediatric intensive care unit of a regional Hong Kong hospital.

Arikan-Akcan $\mathrm{A}^{9}$ showed an incidence of $82 \%$ of AKI in critically ill patients of Texas children's Hospital, USA. This study had modified the RIFLE criteria for paediatric patients as pRIFLE and suggested that majority of critically ill children develop acute kidney injury early in the course of intensive care. Few studies ${ }^{9,24,25}$ had taken the first day creatinine as baseline and in those cases where the SCr levels were either missed or unavailable, it was calculated using the Modification of Diet in Renal Disease (MDRD) formula. In our study, we have taken the baseline SCr by reverse calculation from the standard GFR for the given age and sex as recommended by $\mathrm{KDIGO}^{26}$. This was done to maintain uniformity while grading patients for AKI based on AKIN classification and pRIFLE classification and also to make them comparable. MDRD formula is mainly used for adults while for patients less than 18 years and children, Schwartz formula is recommended, which has better precision and accuracy. This may be one of the reasons for high incidence of AKI in our study. A pre-morbid 'baseline' creatinine is required in order to diagnose and stage acute kidney injury (AKI) using the RIFLE classification. Estimation of baseline creatinine by solving the (MDRD) equation assuming a glomerular filtration rate of $75 \mathrm{ml} / \mathrm{min} / 1.73 \mathrm{~m}^{2}$ has been widely used but never validated ${ }^{27}$. Also, GFR is a more sensitive indicator than $\mathrm{SCr}$ as measure of $\mathrm{AKI}$ and this may be the reason for higher incidence of AKI according to pRIFLE classification. This high incidence may also 
be attributed to our study population who were critically ill (our hospital being a tertiary care center) and thus more prone for AKI. Most of the critically ill patients have subclinical dehydration on admission due to poor oral intake making them prone for elevated serum creatinine levels. Thus, there may be a high chance of misclassification of these patients as non-AKI based on the first creatinine value on admission ${ }^{28}$. There are at least 35 definitions for $\mathrm{AKI}$ in the medical literature which gave rise to wide variation in reported incidence. Clinicians should exercise caution when classifying patients with $\mathrm{AKI}$ as per any of the classification system when a baseline $\mathrm{SCr}$ is unknown. It would be important to consider the goal of AKI classification when selecting a baseline. For clinical purposes, it may be important 'not to miss' any case of potential AKI, so it would be prudent to use the classification with better sensitivity. In developing countries, where malnutrition is very much prevalent, using classification based on SCr may lead to erroneous results, as $\mathrm{SCr}$ also depends on muscle mass.

In our study, there was higher incidence of AKI in younger patient but this was not significant statistically which might be due to small sample size. In a study carried out by Mehta et $\mathrm{a}^{24}$ the mean age of patients with AKI was 24 months whereas in patients with no AKI the mean age was 48 months. In this study, the age group of patients included in the study was one month to 18 years. Similarly, in a study done by Arikan-Akcan A et al ${ }^{9}$ the mean age of patients with AKI was 6.4 years among 150 patients of age group one month to 21 years. In study by Mehta ${ }^{24}$ where $95.9 \%$ patients of AKI had ATN.

The overall mortality rates of patients with AKI (according to pRIFLE and AKIN classifications) were statistically higher than that in non-AKI patients. It was found that as the category of AKI (graded as per pRIFLE) increases, the risk of mortality in patients' increases. It was seen that mortality nearly doubles as patient progresses to injury and failure from risk category. This was, however, not noted among the increasing grade of AKI as per AKIN classification. Ideally any classification, with increasing grades, shows more severity and thereby, should have poorer outcomes. However, this was not the case in AKIN classification.
The study by Arikan-Akcan A concluded as having no difference in overall mortality rates between patients of $\mathrm{AKI}(14.6 \%)$ and those without having $\mathrm{AKI}(11.1 \%)^{9}$. However, patients with pRIFLEmax injury or failure had twice the mortality than patients with pRIFLEmax risk or controls. The study by Hui et al concluded that mortality in patients with $\mathrm{AKI}$ was $12 \%$ compared to two percent in those without $\mathrm{AKI}^{25}$.

In both the above studies $^{9,25}$, pRIFLE was used to classify patients in AKI. None of the results have used the AKIN classification. Any factor that potentially affects mortality during PICU stay could confound the association between AKI and mortality. Also, the initial design of RIFLE was not to predict mortality, but provide a classification scheme to identify various degrees of clinical severity. Moderate agreement was seen during staging of AKI patients by either pRIFLE or AKIN. Only one patient was misclassified by pRIFLE which was identified as AKI by AKIN classification.

\section{Conclusion}

The pRIFLE criteria detects a greater number of cases with AKI compared to AKIN criteria. Based on severity staging, pRIFLE is more consistent with adverse outcome of patients with AKI compared to AKIN classification. Overall mortality is significant high in patients with AKI compared to patients without AKI using any of the classifications.

\section{Limitations}

Potential limitations of our study include the relatively small sample size of 115 patients. Data was restricted to a single study center. Another potential concern was non-availability of actual baseline $\mathrm{SCr}$ values. We did not apply urine output criteria for AKI. Urine output criteria also have its own limitations like children having non-oliguric renal failure and urine output can get affected by use of diuretics. Lack of unavailability of a gold standard for comparison of the classifications is one of the setbacks; though novel biomarkers are available, none of them has been established as a gold standard. In future these novel biomarkers might come up as reliable markers of AKI or integration of such markers in these classifications might increase the sensitivity and specificity of these classifications.

\section{References}

1. Srivastava RN, Bagga A, Moudgil A. Acute renal failure in north Indian children. Indian J Med Res [Internet]. 1990 Dec [cited 2018 May 2];92:404-8. Available from: http://www.ncbi.nlm.nih.gov/pubmed/2079354
2. Chertow GM, Burdick E, Honour M, Bonventre J V, Bates DW. Acute Kidney Injury, Mortality, Length of Stay, and Costs in Hospitalized Patients. J Am Soc Nephrol [Internet]. 2005 Nov 1 [cited 2018 May 2];16(11):3365-70. Available from: http://www.ncbi. nIm.nih.gov/pubmed/16177006 
3. Hoste EAJ, Clermont G, Kersten A, Venkataraman $\mathrm{R}$, Angus DC, De Bacquer D, et al. RIFLE criteria for acute kidney injury are associated with hospital mortality in critically ill patients: a cohort analysis. Crit Care [Internet]. 2006 [cited 2018 May 2];10(3):R73. Available from: http://ccforum.biomedcentral.com/ articles/10.1186/cc4915

4. Lassnigg A, Schmidlin D, Mouhieddine M, Bachmann LM, Druml W, Bauer P, et al. Minimal changes of serum creatinine predict prognosis in patients after cardiothoracic surgery: a prospective cohort study. J Am Soc Nephrol [Internet]. 2004 Jun [cited 2018 May 2];15(6):1597-605. Available from: http://www.ncbi. nlm.nih.gov/pubmed/15153571

5. Uchino S, Bellomo R, Goldsmith D, Bates S, Ronco C. An assessment of the RIFLE criteria for acute renal failure in hospitalized patients. Crit Care Med [Internet]. 2006 Jul [cited 2018 May 2];34(7):1913-7. Available from: https://insights.ovid.com/crossref? an $=00003246-200607000-00008$

6. Lameire $\mathrm{N}$. The definitions and staging systems of acute kidney injury and their limitations in practice. Arab J Nephrol Transplant [Internet]. 2013 Sep [cited 2018 May 2];6(3):145-52. Available from: http://www. ncbi.nlm.nih.gov/pubmed/24053740

7. Flynn JT. Choice of dialysis modality for management of pediatric acute renal failure. Pediatr Nephrol [Internet] 2002 Jan 1 [cited 2018 May 2];17(1):61-9. Available from: http://www.ncbi.nlm.nih.gov/pubmed/11793137

8. Kellum JA, Levin N, Bouman C, Lameire N. Developing a consensus classification system for acute renal failure. Curr Opin Crit Care [Internet]. 2002 Dec [cited 2018 May 2];8(6):509-14. Available from: http://www. ncbi.nlm.nih.gov/pubmed/12454534

9. Akcan-Arikan A, Zappitelli M, Loftis LL, Washburn KK Jefferson LS, Goldstein SL. Modified RIFLE criteria in critically ill children with acute kidney injury. Kidney Int [Internet]. 2007 May [cited 2018 May 3];71(10):102835. Available from: http://www.ncbi.nlm.nih.gov/ pubmed/17396113

10. Sutherland SM, Byrnes JJ, Kothari M, Longhurst CA Dutta S, Garcia P, et al. AKI in hospitalized children: Comparing the pRIFLE, AKIN, and KDIGO definitions. Clin J Am Soc Nephrol. 2015;10(4):554-61.

11. Joannidis M, Metnitz B, Bauer P, Schusterschitz N Moreno R, DrumI W, et al. Acute kidney injury in critically ill patients classified by AKIN versus RIFLE using the SAPS 3 database. Intensive Care Med [Internet]. 2009 Oct 23 [cited 2018 May 2];35(10):1692-702. Available from: http://www.ncbi.nlm.nih.gov/pubmed/19547955

12. Wang HE, Jain G, Glassock RJ, Warnock DG Comparison of absolute serum creatinine changes versus Kidney Disease: Improving Global Outcomes consensus definitions for characterizing stages of acute kidney injury. Nephrol Dial Transplant [Internet]
2013 Jun [cited 2018 May 3];28(6):1447-54. Available from: https://academic.oup.com/ndt/article-lookup/ doi/10.1093/ndt/gfs533

13. Bagshaw SM, George C, Bellomo R, ANZICS Database Management Committe. A comparison of the RIFLE and AKIN criteria for acute kidney injury in critically ill patients. Nephrol Dial Transplant [Internet]. 2008 May 26 [cited 2018 May 3];23(5):1569-74. Available from: https://academic.oup.com/ndt/articlelookup/doi/10.1093/ndt/gfn009

14. Srinivasa S, Reshmavathi K, Srividya G. A comparison of pRIFLE and AKIN criteria for acute kidney injury in pediatric intensive care unit patients. Int $\mathrm{J}$ Contemp Pediatr [Internet]. 2016 [cited 2018 May 3];3(2):398402. Available from: http://www.ijpediatrics.com/index. php/ijcp/article/view/255

15. Lopes JA, Jorge S. The RIFLE and AKIN classifications for acute kidney injury: A critical and comprehensive review. Clin Kidney J. 2013;6(1):8-14.

16. Zappitelli M, Parikh CR, Akcan-Arikan A, Washburn KK, Moffett BS, Goldstein SL. Ascertainment and epidemiology of acute kidney injury varies with definition interpretation. Clin J Am Soc Nephrol [Internet]. 2008 Jul 9 [cited 2018 May 3];3(4):94854. Available from: http://cjasn.asnjournals.org/cgi/ doi/10.2215/CJN.05431207

17. Hou SH, Bushinsky DA, Wish JB, Cohen JJ, Harrington JT. Hospital-acquired renal insufficiency: a prospective study. Am J Med [Internet]. 1983 Feb [cited 2018 May 3];74(2):243-8. Available from: http:// www.ncbi.nlm.nih.gov/pubmed/6824004

18. Basu RK, Devarajan P, Wong H, Wheeler DS. An update and review of acute kidney injury in pediatrics. Pediatr Crit Care Med [Internet]. 2011 May [cited 2018 May 3];12(3):339-47. Available from: http://content. wkhealth.com/linkback/openurl?sid=WKPTLP:landing page\&an $=00130478-201105000-00014$

19. Askenazi DJ, Ambalavanan N, Hamilton K, Cutter G, Laney D, Kaslow R, et al. Acute kidney injury and renal replacement therapy independently predict mortality in neonatal and pediatric noncardiac patients on extracorporeal membrane oxygenation. Pediatr Crit Care Med [Internet]. 2011 Jan [cited 2018 May 3];12(1):e1-6. Available from: https://insights.ovid. com/crossref?an $=00130478-201101000-00036$

20. Bowers LD, Wong ET. Kinetic serum creatinine assays. II. A critical evaluation and review. Clin Chem [Internet]. 1980 Apr [cited 2018 May 3];26(5):55561. Available from: http://www.ncbi.nlm.nih.gov/ pubmed/7020989

21. Schwartz GJ, Brion LP, Spitzer A. The use of plasma creatinine concentration for estimating glomerular filtration rate in infants, children, and adolescents. Pediatr Clin North Am [Internet]. 1987 Jun [cited 2018 May 3];34(3):571-90. Available from: http://www.ncbi. nlm.nih.gov/pubmed/3588043 
22. Mehta RL, Kellum JA, Shah S V, Molitoris BA, Ronco C, Warnock DG, et al. Acute Kidney Injury Network: report of an initiative to improve outcomes in acute kidney injury. Crit Care [Internet]. 2007 [cited 2018 May 3];11(2):R31. Available from: http://ccforum. biomedcentral.com/articles/10.1186/cc5713

23. Bryman A, Cramer D. Quantitative Data Analysis with SPSS for Windows: A Guide for Social Scientists [Internet]. London and New York: Routledge Tailor \& Francis Group; 2011. Available from: https:// www.researchgate.net/publication/275412490_ Quantitative_Data_Analysis_with_SPSS_for_ Windows_A_Guide_for_Social_Scientists

24. Mehta P, Sinha A, Sami A, Hari P, Kalaivani M, Gulati A, et al. Incidence of acute kidney injury in hospitalized children. Indian Pediatr [Internet]. 2012 Jul [cited 2018 May 2];49(7):537-42. Available from: http://www.ncbi. nlm.nih.gov/pubmed/22317984

25. Hui WF, Chan WKY, Miu TY. Acute kidney injury in the paediatric intensive care unit: identification by modified RIFLE criteria. Hong Kong Med $\mathrm{J}=$
Xianggang yi xue za zhi [Internet]. 2013 Feb [cited 2018 May 2];19(1):13-9. Available from: http://www. ncbi.nlm.nih.gov/pubmed/23378349

26. KDIGO. KDIGO Clinical Practice Guideline for Acute Kidney Injury. Kidney Int Suppl [Internet]. 2012 [cited 2018 May 3];2(1):1-138. Available from: http://www. kidney-international.org

27. Bellomo R, Ronco C, Kellum JA, Mehta RL, Palevsky $P$, Acute Dialysis Quality Initiative workgroup. Acute renal failure - definition, outcome measures, animal models, fluid therapy and information technology needs: the Second International Consensus Conference of the Acute Dialysis Quality Initiative (ADQI) Group. Crit Care [Internet]. 2004 Aug [cited 2018 May 3];8(4):R204-12. Available from: http:// ccforum.biomedcentral.com/articles/10.1186/cc2872

28. Srisawat N, Kellum JA. Acute kidney injury: definition, epidemiology, and outcome. Curr Opin Crit Care [Internet]. 2011 Dec [cited 2018 May 3];17(6):548-55. Available from: https://insights.ovid.com/crossref? an $=00075198-201112000-00003$. 